\title{
Sat-nav neurons tell bats where to go
}

\section{Long-hypothesized brain cells give bats their distance and angle to a location.}

\section{Alison Abbott}

12 January 2017

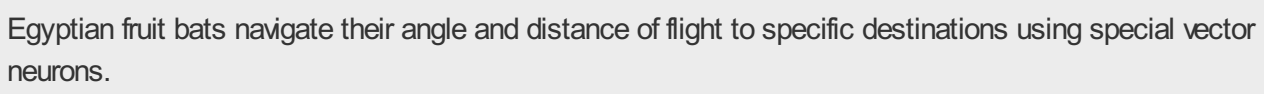

Bats have brain cells that keep track of their angle and distance to a target, researchers have discovered. The neurons, called 'vector cells', are a key piece of the mammalian's brain complex navigation system — and something that neuroscientists have been seeking for years.

Our brain's navigation system has many types of cells, but a lot of them seem designed to keep track of where we are. Researchers know of 'place' cells, for example, which fire when animals are in a particular location, and 'head direction' cells that fire in response to changes in the direction the head is facing. Bats also have a kind of neuronal compass that enables them to orient themselves as they fly.

The vector cells, by contrast, keep spatial track of where we are going. They are in the brain's hippocampus, which is also where 'place' and 'head-direction' cells were discovered.

That's a surprise, considering how well this area has been studied by researchers, says Nachum Ulanovsky, who led the team at the Weizmann Institute of Science in Rehovot, Israel, that discovered the new cells. His team published their findings in Science on 12 January ${ }^{1}$.

\section{0-degree approach}

Finding the cells "was one of those very rare discovery moments in a researcher's life," says Ulanovsky. "My heart raced, I started jumping around." The trick to finding them was a simple matter of experimental design, he says.

Most navigation research has been carried out in rats, which tend to slink close to walls. No-one had monitored animals' brains while they navigated to a goal in the centre of a room.

But Ulanovsky's team developed techniques for studying the system in Egyptian fruit bats (Rousettus aegyptiacus), whose heads are large enough to carry the experimental equipment as the animals fly towards a centrally located perch.

The team screwed tiny wireless devices into the skulls of three bats to track their flight paths and collect data from electrodes implanted inside their hippocampi.

They released the bats into a large flight room with a perch bearing bananas, the fruit bat's favourite meal, at its centre. Freed from smaller cages, the bats would exuberantly loop-the-loop before heading towards the food. Having the goal in the centre of the room, so that approach paths covered 360 degrees, turned out to be the essential element in pinpointing the vector cells. It meant that the team could verify that the same neurons were firing whatever the direction of approach.

\section{Hidden goal}

In one experiment, the researchers were able to monitor 309 neurons in the three bats. Around one-third of these neurons were simple place cells, firing when the bats flew over a particular spot. But 58 were tuned to the angular direction of the destination. A majority of these vector cells fired at their highest rates when the bat was heading directly to the goal. The neurons remained tuned to goal direction throughout the bats' long and convoluted flights. Forty-nine neurons responded to distance to goal, and most fired at their highest rates when the bat was within two metres. Twenty-four cells were tuned to both angle and distance. 
need to remember where that target was, says Ulanovsky.

To mimic this scenario, the team hid the fruit stand against a wall and fixed a plastic curtain floor-to ceiling in front of it. The curtain was opaque to vision and echolocation and did not let odours through. The bats were able to fly around it. But on one side of it, they could no longer see the bananas, Still, when the bats were on this side, the vector cells maintained their tuning to the remembered goal.

"This suggests that the vector cells are indeed memory-based rather than sensory-based," says Ulanovsky.

\section{A window into Alzheimer's?}

The new find "makes us rethink how the navigation system works as a whole," says Edvard Moser, who is founding director of the Kavli Institute for Systems Neuroscience in Trondheim, Norway. Moser shared the 2014 Nobel Prize in Physiology or Medicine for key discoveries in brain navigation.

Moser says researchers will now hope to find the same cells in rats. The discovery raises a slew of questions about how navigation circuitry works as a whole. The brain might also have other ways to compute goal trajectories without having specialized cells for it, he says.

"This is a fascinating finding," adds cognitive neuroscientist Howard Eichenbaum of Boston University, Massachusetts. In 1987, Eichenbaum identified cells in rat brains that seem to fire when rats approach a target ${ }^{2}$. In his view, the connection with the hippocampus suggests that navigation may just be "a really complicated memory task." Perhaps, researchers think, this is why people with Alzheimer's disease lose their way easily — along with losing their memories.

Nature | doi:10.1038/nature.2017.21275

\section{References}

1. Sarel, A., Finkelstein, A., Las, L. \& Ulanovsky, N. Science http://dx.doi.org./10.1126/science.aak9589 (2017).

2. Eichenbaum, H., Kuperstein, M., Fagan, A. \& Nagode, J. J. Neurosci. 7, 716-732 (1987). 